
Brasília, v.23, n.1, p.72-75, jan.-mar. 2005.

\title{
Reação de acessos de pimentão e pimentas ao oídio (Oidiopsis taurica)
}

\author{
Sally F. Blat ${ }^{1}$; Cyro Paulino da Costa ${ }^{1}$; Roland Vencovsky²; Fernando César Sala ${ }^{1}$ \\ ${ }^{1}$ USP/ESALQ, Depto. Produção Vegetal, C. Postal 09, 13418-900 Piracicaba-SP; ${ }^{2}$ USP/ESALQ, Depto. Genética; E-mail: \\ sfblat@esalq.usp.br; cpcosta@terra.com.br;
}

\section{RESUMO}

O oídio causado pelo fungo Oidiopsis taurica é uma das principais doenças no gênero Capsicum spp. Seus danos podem causar desfolha de até $75 \%$ e perdas de até $40 \%$ em produção. Seu controle através de fungicidas tem se mostrado ineficaz, sendo a resistência genética a melhor alternativa. Poucas fontes de resistência já foram identificadas em Capsicum annuum. Neste trabalho avaliou-se os acessos da coleção de Capsicum spp. do banco de germoplasma da USP/ESALQ quanto às suas reações ao oídio e identificar novas fontes de resistência. O experimento foi conduzido em casa de vegetação em condições severas de ocorrência do patógeno. Durante a fase de frutificação foi feita a avaliação das reações, através de uma escala de notas, de 1 (resistente) a 5 (altamente suscetível). Dos 156 acessos testados, 53 foram considerados resistentes, sendo representados por 5 acessos em C. annuum, $31 \mathrm{em} \mathrm{C.} \mathrm{baccatum} \mathrm{e} 17 \mathrm{em}$ $C$. chinense. Dentre os acessos resistentes em $C$. annuum, a variedade dihaploide HV-12 mostrou-se como a mais resistente. Duas novas fontes de resistência se destacaram em C. annuum, \#124 e Chilli. Esses acessos mostraram um mecanismo diferenciado de resistência, apresentando uma reação de hipersensibilidade ao patógeno. Os híbridos comerciais Reinger, Nathalie, Margarita, Magali R e Magda foram classificados como suscetíveis a altamente suscetíveis. Grande parte dos acessos resistentes de $C$. baccatum e $C$. chinense apresentaram desfolha em conseqüência do mecanismo de hipersensibilidade.

Palavras-chave: Capsicum spp., Leveillula taurica (Lev.) Arn, resistência genética.

\begin{abstract}
Reaction of sweet and hot pepper accesses to powdery mildew (Oidiopsis taurica)
\end{abstract}

Powdery mildew caused by Oidiopsis taurica is one of the major diseases of Capsicum spp., causing damage due to defoliation of up to $75 \%$ and yield losses of up to $40 \%$. Disease control with fungicide is inefficient, genetic resistance being the best way of control. Few resistant sources have been identified in Capsicum annuиm. Capsicum spp. collection accesses of USP/ESALQ germplasm bank were screened in their reaction and identification of new resistance sources. The screening was carried out in a greenhouse under high inoculum pressure. Disease was assessed during fruit production using a severity scale varying from 1 (resistant) to 5 (highly susceptible). From 156 accesses evaluated 53 were resistant, represented by five accesses in C. annuum, 31 in C. baccatum and 17 in $C$. chinense. The hv-12 was the most resistant among the C. annuum accesses. Two new resistant sources were found in C. annuum, \# 124 and chilli. These accesses showed different resistance mechanisms through hypersensitive host reaction. The commercial hybrids Reinger, Nathalie, Margarita, Magali R and Magda were susceptible or highly susceptible. Most of C. baccatum and $C$. chinense resistant accesses showed defoliation as a consequence of hypersensitive mechanism.

Keywords: Capsicum spp., Leveillula taurica (Lev.) Arn., genetic resistance.

(Recebido para publicação em 4 de janeiro de 2004 e aceito em 29 de outubro de 2004)

$\mathrm{O}$ oídio do pimentão e pimentas, causado pelo fungo Leveillula taurica (Lev.) Arn., anamorfo Oidiopsis taurica (Lev.) Salmon, tem sido considerado a doença mais problemática sob cultivo protegido no Brasil e em outros países, causando desfolha de até 75\% (Damicone e Sutherland, 1999) e perdas de até $40 \%$ em produção (Daubeze et al., 1995).

Além do pimentão, o patógeno infecta outras culturas como tomate (Correl et al., 1987), berinjela, batata (Palti, 1988), alcachofra, pepino (Molot e Lecoq, 1986), quiabo, algodão, fava (Nour, 1958), alho porro (Palti, 1988, Daubeze et al., 1995).

No Brasil, o primeiro relato de oídio em pimentão foi na região do Distrito Federal em 1994 (Boiteux et al., 1994).
Plantios sucessivos de pimentão e tomate nas regiões produtoras resultaram no estabelecimento do oídio. Em pimentão a doença não ocorre na fase juvenil (Souza e Café Filho, 2000). Os esporos de Oidiopsis taurica penetram pelos estômatos e possuem a capacidade de germinar em condições de baixa umidade relativa (40 a 90\%). Além disso, é o único entre os oídios que tem hábito de crescimento interno (Smith et al., 1999). Os sinais iniciam-se na face inferior das folhas, representados por esporulação pulverulenta branca. $\mathrm{Na}$ face superior foliar correspondente surgem manchas cloróticas e o pecíolo amarelece, ocorrendo em seguida, abscisão foliar (Palti, 1988; Daubeze et al., 1995). A injúria dos frutos pelo sol é um dos mais marcantes e prejudiciais sintomas de oídio do pimentão em decorrência da desfolha.

Fungicidas sistêmicos não têm sido eficazes no controle de L. taurica e podem promover o surgimento de raças resistentes ao produto (Bergamin Filho et al., 1995). Dessa forma, a melhor maneira de controle seria pelo uso de variedades resistentes. As fontes encontradas em C. annuит, não são adequadas por apresentarem resistência parcial (Daubeze et al., 1995; Shifriss et al., 1992). As melhores fontes de resistência foram identificadas em Capsicum chinense e C. baccatum (Lima, 2002, Souza e Café Filho, 2003). A variedade dihaploide HV-12 tem sido a única fonte estável de resistência descrita em $C$. annuum (Shifriss et al., 1992; Bechir, 1993; Souza e Café-Filho, 2003). O 
modo de herança da resistência ao oídio é de natureza complexa, envolvendo pelo menos três genes (Shifriss et al.,1992), com ação gênica aditiva e epistática (Daubeze et al., 1995).

Souza e Café Filho (2003), identificaram oito acessos imunes a L. taurica: HV-12, 4638, CNPH 36, 38, 50, 52, 279 e 288 . Em C. annuum $70 \%$ dos acessos foram moderadamente suscetíveis enquanto $C$. baccatum, $C$. frutescens e $C$. chinense apresentaram alta ocorrência de acessos resistentes. Lima (2002) testando a reação de 104 acessos de Capsicum spp. a L. taurica, sob condições naturais de infecção, verificou que $68 \%$ dos acessos de C. annuum foram altamente suscetíveis. Em C. baccatum, C. chinense e $C$. frutescens acessos com reações moderadamente suscetíveis e/ ou altamente suscetíveis não foram identificados, sendo a maioria altamente resistente.

A variedade HV-12, como descrito anteriormente, tem se mostrado uma excelente fonte de resistência. Apesar disso apresenta frutos tipo cônico longo com dois a três lóculos e polpa extremamente fina, que são características nada atrativas para o mercado de pimentão.

Neste trabalho foram avaliados os acessos da coleção de Capsicum spp. do banco de germoplasma da USP/ESALQ quanto às suas reações ao oídio e identificar novas fontes de resistência.

\section{MATERIAL E MÉTODOS}

Cento e cinqüenta e seis acessos do Banco de Germoplasma de Capsicum da USP/ESALQ, sendo 99 de C. annuum, 37 de $C$. baccatum e 20 de $C$. chinense foram avaliados quanto às suas reações a Oidiopsis taurica.

$\mathrm{O}$ experimento foi conduzido em casa-de-vegetação da ESALQ em Piracicaba. As mudas produzidas em bandejas de poliestireno expandido foram transplantadas, no mês de novembro, para vasos plásticos de oito litros contendo uma mistura de areia lavada, vermiculita e turfa na proporção de $3: 2: 1$, respectivamente. O delineamento experimental foi em blocos casualizados com parcelas de uma planta por vaso e quatro repetições.
Tabela 1. Acessos de Capsicum spp. identificados como resistentes ao oídio (Oidiopsis taurica). Piracicaba, ESALQ, 2001.

\begin{tabular}{ll}
\hline Espécie & Acessos \\
\hline C. annuum & HV-12, \# 124, Chili, Catie 8063, Jalapeno 2. \\
\hline C. baccatum & Aji Amarillo \#67, Aji Limo, Aji Hojo \# 268, Arivivi \# 212, \\
BGH 0620, BGH 1022, BGH1037, BGH 1603, BGH 1675, \\
BGH 2994, BGH 4176, BGH 4301, BGH 4366, BGH 5025, \\
Guarnica \# 243, BGH 592, ICA \#65, Pimenta ESALQ \\
\# 147, Balão Barra Vermelha, Pimenta Piranga, Cambuci, \\
Coração, Yerba Mala \# 251, ICA \# 60, Muripi IH 1492, \\
Chapéu de Bispo, RFG/FAO 553, Aji \# 286, Aji Amarillo \# \\
267, Aji Amarillo \#60, Aji \# 284 \\
Bode, Habanero, ICA \# 39, Muripi IH 1477, Muripi IH \\
1490, Pimenta Doce IH 1749, Pimenta Cheiro ESALQ 105, \\
Pimenta Doce ESALQ \# 106, Pimenta Doce IH 1750, \\
Pimenta Doce IH 1766, Pimenta n 2, Pimenta n 5, Rabo \\
de Macaco, Santarem \# 50, PI 152225, Pimenta Cheiro \\
Laranja, Pimenta Cheiro 2
\end{tabular}

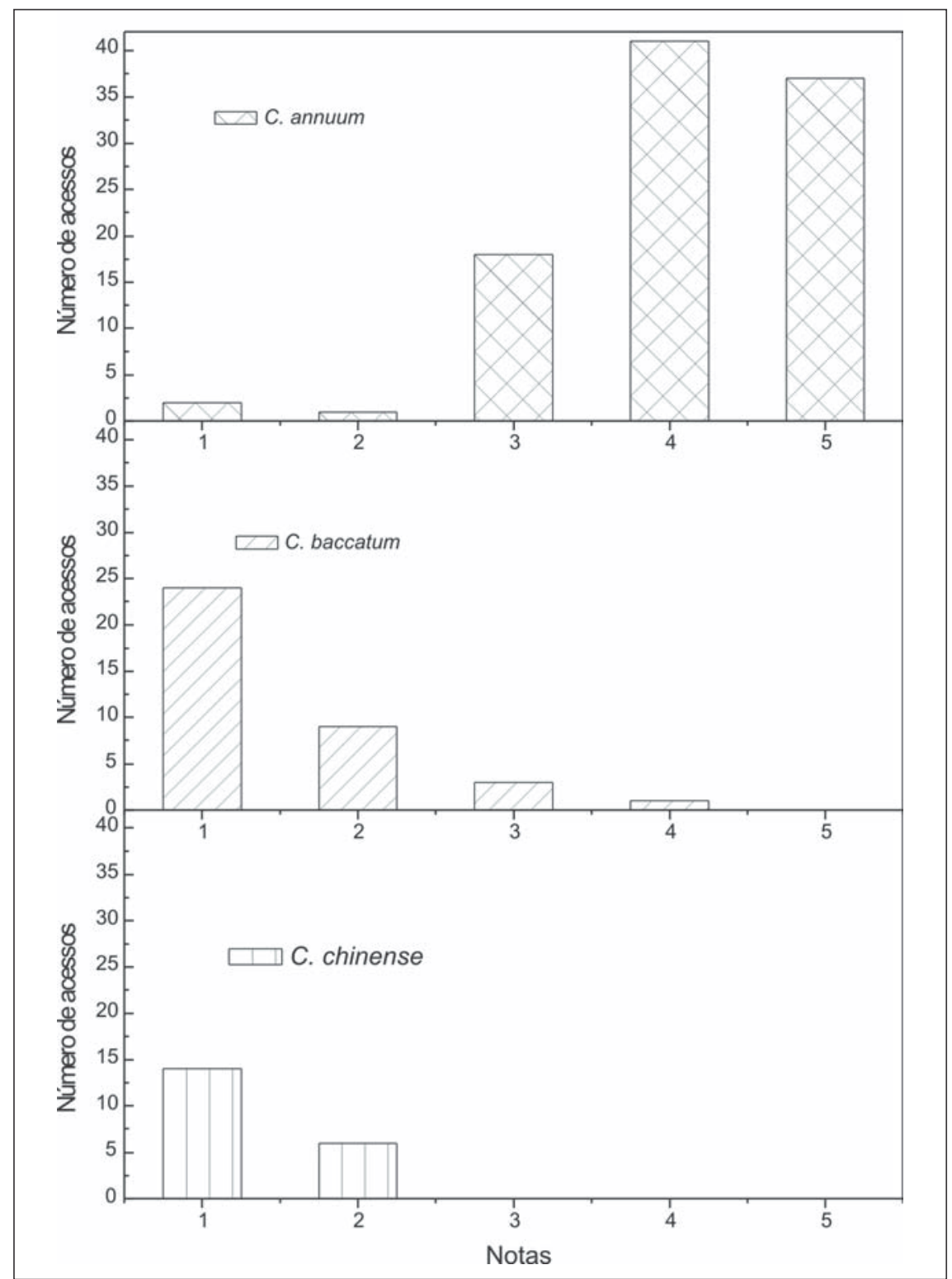

Figura 1. Distribuição em número de acessos de C. annuum, C. baccatum e C. chinense, de acordo com a escala de notas. Piracicaba, ESALQ, 2001. 


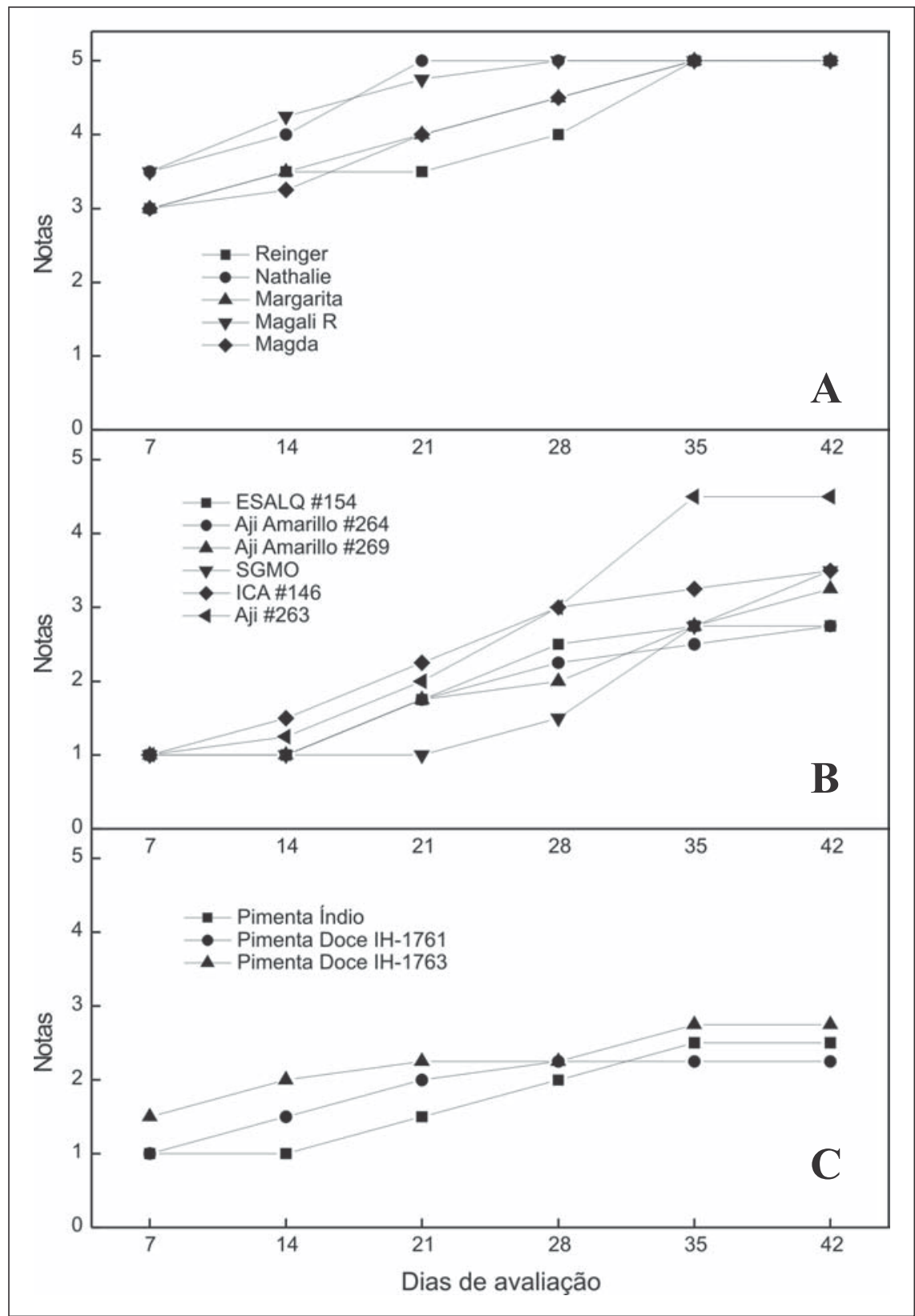

Figura 2. Progresso do oídio em acessos moderadamente suscetíveis a altamente suscetíveis de Capsicum annuum (A) (representados pelos híbridos comerciais), C. baccatum (B) e C. chinense (C). Piracicaba, ESALQ, 2001.

A epidemia de oídio ocorreu a partir de inóculo inicial mantido em plantas de pimentão suscetíveis e com alto grau de esporulação. Essas plantas disseminadoras do patógeno foram intercaladas na proporção de uma planta suscetível para cada quinze dos acessos a serem avaliados.

As reações dos acessos ao patógenos foram avaliadas a partir do surgimento dos sintomas, iniciando-se na fase de formação dos frutos, aos 80 dias após a semeadura, em intervalos de sete dias, cetível, com $51 \%$ ou mais da área foliar afetada. Os híbridos Margarita e Magali $\mathrm{R}$ foram usados como testemunhas suscetíveis.

As reações expressas pelas escalas de notas foram analisadas pelo método GLIM Versão 4.09 (Fransis et al., 1993). O software "GLIM" utiliza-se de um modelo logístico acumulado, onde se supõe que a distribuição original dos dados é Poisson. Deste modo, com as estimativas dos pontos de corte da análise original, caracterizou-se a reação dos acessos resistentes (notas entre $1 \mathrm{e}$ 2) através das estimativas dos efeitos dos parâmetros (os acessos) ajustados e seus respectivos desvios-padrão.

\section{RESULTADOS E DISCUSSÃO}

Dos 156 acessos testados 53 foram considerados resistentes. Em C. annuum se obteve a menor proporção onde apenas cinco dos 99 acessos foram resistentes. Nas demais espécies o inverso ocorreu. Para C. baccatum, 31 entre os 37 acessos foram resistentes e, em $C$. chinense 17 dos 20 acessos foram resistentes (Tabela 1, Figura 1).

A baixa freqüência de resistência ao oídio observada em $C$. annuum confirma os resultados obtidos por Lima (2002) e Souza e Café-Filho (2003). A alta ocorrência de suscetibilidade pode ser devida ao intenso processo de domesticação e seleção, com possível erosão genética e aumento da vulnerabilidade a doenças (Reifschneider et al., 2000).

A variedade HV-12 mostrou ser excelente fonte de resistência para o melhoramento de pimentão à $O$. taurica, obtendo nota 1 da primeira à última avaliação (Tabela 1). A sua resistência é expressa pelo mecanismo de restrição à infecção e colonização do patógeno e retenção foliar (Shifriss et al., 1992). A resistência duradoura do HV-12 foi confirmada no Brasil (Souza e Café-Filho, 2003; Lima, 2002), na Tunísia (Bechir, 1993), em Israel (Shifriss et al., 1992), França e Itália (Daubeze et al., 1995).

Na espécie C. annuum, além do HV12 , outros quatro acessos foram considerados resistentes, destacando-se principalmente as pimentas Chilli e \#124, que apresentaram médias de 1,75 e 2,25 
aos 42 dias de avaliação ou 122 dias de ciclo (Tabela 1). Estas pimenteiras apresentaram sintomas caracterizados por pequenas manchas necróticas sem esporulação visível, conhecidas na literatura como "fleck". Esse sintoma e reação são resultantes da hipersensibilidade do hospedeiro ao patógeno, o qual constitui num possível e efetivo mecanismo de defesa. Há a infecção pelo patógeno, porém ocorre morte celular no local de penetração. (Carver et al., 1995; Stadnik e Rivera, 2001). De acordo com Lima (2002), acessos resistentes, na presença do patógeno, podem exibir manchas cloróticas sem esporulação. Esta reação de hipersensibilidade pode ocorrer quando existe forte pressão do inóculo, como ocorrido no presente estudo.

As reações dos demais acessos, na espécie C. annuum, foram na grande maioria altamente suscetíveis (Figura 1) atingindo nota máxima 5 geralmente entre os 35-45 dias de avaliação ou 115 122 dias do ciclo da cultura (Figura 2) (Blat, 2004). Os híbridos comerciais Reinger, Nathalie, Margarita, Magali R e Magda foram classificados como suscetíveis a altamente suscetíveis, concordando com os resultados de Lima (2002) e Souza e Café-Filho, 2003.

Na espécie $C$. baccatum, apenas seis dos 37 acessos foram considerados de moderadamente suscetíveis a suscetíveis (Figura 2), mostrando que a espécie pode ser uma boa fonte de resistência a ser utilizada no melhoramento para resistência a $O$. taurica. Dentre esses seis acessos observa-se que cinco alcançaram nota média máxima de 3,5. Apenas o acesso Aji \# 263 se destacou pela sua alta suscetibilidade apresentando média 4,50 (Figura 2).

Em C. chinense, apenas os acessos Pimenta Índio, Pimenta Doce IH-1761 e Pimenta Doce IH-1763 apresentaram reações diferenciadas dos demais testados, sendo considerados moderadamente suscetíveis (Figura 2).

O grau de severidade da doença dos acessos suscetíveis de $C$. baccatum e $C$. chinense caracterizou-se por ser extremamente reduzido se comparado ao de C. annuum. A média máxima generalizada de notas aos 42 dias de avaliação ou 122 de ciclo, para os acessos suscetíveis de $C$. baccatum não ultrapassou 3,5. Em C. chinense esta média foi ainda inferior, sendo no máximo 2,75 (Figura 2).

A reação de hipersensibilidade também foi observada na maioria dos acessos de $C$. baccatum e $C$. chinense. A desfolha possivelmente foi causada pela biossíntese de etileno resultante da interação hospedeiro patógeno (Reuveni et al., 1974). Lima (2002) também constatou o efeito da desfolha atribuindo o fato, além da hipersensibilidade, à característica fenológica da planta e variações de umidade e temperatura. Este tipo de mecanismo é válido, pois elimina a fonte de inóculo, reduzindo a epidemia.

\section{AGRADECIMENTOS}

A FAPESP pelo suporte financeiro e bolsa de doutorado.

\section{LITERATURA CITADA}

BECHIR, A.M. Evaluation of pepper genotypes to Leveillula taurica Lev. (Arn.) resistance in Tunisia. Capsicum and Eggplant Newsletter, v.12, p.81-82, 1993.

BERGAMIN FILHO, A.; KIMATI, H.; AMORIM L. Manual de fitopatologia: princípios e conceitos. 3 ed. São Paulo: Ceres, v.1, 1995. 919 p.

BLAT, S.F. Herança da reação de Capsicum spp. ao oídio (Leveillula taurica(Lev.) Arn.). 2004. 153 f. (Tese doutorado) - USP, ESALQ, Piracicaba. CARVER, T.L.W.; ZEYEN, R.J.; LYNGKJAER, M.F. Plant cell defenses to powdery mildew of Graminae. Aspects of Applied Biology, v.42, p.257266, 1995.
CORRELL, J.C.; GORDON, T.R.; ELLIOTT, V.J. Host range, specificity, and biometrical measurements of Leveillula taurica in California. Plant Disease, v.71, n.3, p.248-251, 1987.

DAUBEZE, A.M.; HENNART, J.W.; PALLOIX, A. Resistance to Leveillula taurica in pepper (Capsicum annuum) is oligogenically controlled and stable in Mediterranean regions. CD-ROM. Plant Breeding, v.114, v.4, p.327-332, 1995.

DAMICONE, J.P.; SUTHERLAND, A.J. First report of pepper powdery mildew caused by Leveillula taurica in Oklahoma. Plant Disease, v.83, p.1072, 1999.

FRANSIS, B.; GREEN, M.; PAYNE, C. The GLIM systems: Reliese 4 Manual. (Eds B. Fransis; M. Green; C. Payne). Oxford Universus Press, Oxford.

LIMA, M.L.P Resistência genética e aspectos epidemiológicos, fisiológicos e anatômicos da infecção de Oidiopsis taurica em Capsicum spp. 2002. 130 f. (Tese mestrado) - UnB, Inst. Biociências, Brasília.

MOLOT, P.M., LECOQ, H. Les Oidiums des Cucurbitacées. Données bibliographiques. Travaux préliminairees. Agronomie, v.6, p.355362, 1986.

NOUR, M.A. Studies on Leveillula taurica (Lév.) Arn. and other powdery mildews. Transactions of the British Mycological Society. v.41, p.17-38, 1958.

PALTI, J. The Leveillula mildews. Botanical Review, v.54, p.423-535, 1988.

REIFSCHNEIDER, F.J.B. Capsicum: Pimentas e pimentões no Brasil. Brasília: Embrapa, 2000. 113 p.

SHIFRISS, C.; PILOWSKY, M.; ZACKS, J.M. Resistance to Leveillula taurica mildew (=Oidiopsis taurica) in Capsicum annuum. Phytoparasitica, v.20, n.4, p.279-283, 1992.

SMITH, R.; KOIKE, S.T.; DAVIS. M.; SUBBARAO, K.; LAEMMLEN, F. Several fungicides control powdery mildew in peppers. California Agriculture, v.53, n.6, p.40-43, 1999.

SOUZA, V.L.; CAFÉ FILHO, A.C. Efeito do estádio fenológico e da pressão de inóculo na reação de genótipos de Capsicum a Oidiopsis taurica. Fitopatologia Brasileira, Brasília, v.25, p.404, 2000. (resumo).

SOUZA, V.L.; CAFÉ-FILHO, A.C. Resistance to Leveillula taurica in genus Capsicum Plant Pathology, v.52, p.613-619, 2003.

STADNIK, M.J.; RIVERA, M.C. Oidios. Jaguariúna: Embrapa Meio Ambiente. p.79-118, 2001.

ULLASA, B.A.; RAWAL, R.D.; SOHI, H.S.; SINGH, D.P. Reaction of sweet pepper genotypes to anthracnose, cercospora leaf spot, and powdery mildew. Plant Disease, v.65, n.7, p.600-601, 1981. 